\title{
WOMEN'S ROLE IN STRENGTHENING RELIGIOUS ACTIVITIES THROUGH EMPOWERMENT OF THE HOUSE OF TAHFIZ DARUL JANNAH
}

\section{Irwandi}

IAIN Batusangkar

E-mail: irwandi@iainbatusangkar.ac.id

\section{Zulamri}

UIN Suska Riau

E-mail:

romimaimori@iainbatusangkar.ac.id

\section{Romi Maimori \\ IAIN Batusangkar \\ E-mail: \\ romimaimori@iainbatusangkar.ac.id}

\section{Tri Yuliani}

IAIN Batusangkar

E-mail: triyuliani@iainbatusangkar.ac.id
Abstract: The role of women in Minangkabau plays a strategic place in fostering people, including in younger generation in "tahfiz's house" activities. Problem that usually arises is the authority of women in doing activities outside, especially in the Nagari Tanjung Barulak. The women in Nagari Tanjung Barulak are not only active at home as Limpapeh Rumah Gadang who act as mothers for the children but also as "mothers" for children in Nagari. The research method used is a qualitative research method with a descriptive approach. The techniques of Data collection are interviews, observation and documentation. The result of research shows that women has vital roles in stir Tahfiz's house in Nagari Tanjuang Barulak, Batipuh District. It means there was no contradiction in fostering people in terms of religion. In terms of Minangkabau customs, the role of women also has its own place, and can play a role in two functions, namely the function as mother or Bundo Kanduang in the community and family as well as Bundo Kanduang in the midst of the people.

Keywords: Tahfidz's House, Women and Women empowerment.

\section{PENDAHULUAN:}

Semenjak lahirnya Peraturan Daerah Kabupaten Tanah Datar Nomor. 2 Tahun 2007 Tentang Pandai Baca Tulis Alquran Bagi Peserta Didik Pada Pendidikan Dasar Dan Menengah Serta Calon Penganten. Sehinggga hal ini mendorong pemerintah daerah untuk lebih menekankan pentingnya baca tulis al-quran bagi seluruh masyarakat Kabupaten Tanah Datar.
Menindaklanjuti peraturan daerah tersebut bagian Kesejahteraan Rakyat (Kesra) Setda Kabupaten Tanah Datar beserta Kementerian Agama Kabupaten Tanah Datar bersama-sama membuat terobosan baru tentang pengkajian Al-quran melalui "Pondok Alquran". kelahiran "Pondok Alquran" yang bertujuan untuk menindaklanjuti peraturan daerah dimaksud memiliki beberapa kegiatan pokok diantaranya: 
pendidikan tilawatil Quran, pembinaan tahfizul Quran, pembinaan khattil Quran, pembinaan khutbah jumat dan fahmil quran. Peserta dari pondok alquran dimaksud berasal dari santri taman pendidikan Al-quran baik yang belum khattam al-quran maupun yang sudah khatam Al-Quran, sesuai dengan kemampuan para santri. Disamping menindaklanjuti Perda tersebut pendirian "Pondok Alquran" juga bertujuan untuk mempersiapkan khafilah Kabupaten Tanah Datar mengikuti event Musabaqah Tilawatil Qur'an (MTQ) Tingkat Propinsi Sumatera Barat. Begitu pentingnya pendirian "Pondok Alquran" tersebut maka "Pondok Alquran" didirikan disetiap kecamatan yang ada di Kabupaten Tanah Datar dengan pendanaan dianggarkan dalam APBD Kabupaten Tanah Datar setiap tahunnya. Dalam perjalanannya perkembangan "Pondok Alquran" di Kabupaten Tanah Datar mulai menunjukkan hasil yang memuaskan karena "Pondok Alquran" tersebut tidak hanya ada di setiap kecamatan tapi juga sampai ke nagari-nagari dan jorong-jorong yang ada di Kabupeten Tanah Datar pendirian pondok AlQuran di nagari-nagari di prakarsai oleh wali nagari beserta unsur- alim ulama, unsur Pemuda, unsur Cadiak Pandai, unsur bundo kanduang, pengurus Masjid/mushalla/surau beserta masyarakat.

Pendirian pondok Al-quran yang dimulai semenjak tahun 2009, langsung di bawah binaan Lembaga Pengembangan Tilawatil Quran (LPTQ) Kabupten Tanah Datar, dengan segala bentuk kegiatan pokok telah dilakukan sesuai petunjuk teknis yang di keluarkan oleh Pemerintah Daerah bersama kementerian agama
Kabupaten Tanah Datar, dan LPTQ Kab. Tanah Datar telah menampakkan hasil yang memuaskan diantaranya kabupaten Tanah Datar selalu menduduki peringkat kedua dalam pelaksanaan MTQ Nasional Tingkat Propinsi Sumatera Barat setelah Kota Padang, dan telah banyak mengutus para santri "Pondok Alquran" mewakili Propinsi Sumatera Barat mengikuti MTQ Nasional yang diadakan oleh pemerintah pusat. prestasi ini tentunya menambah kepercayaan Pemerintah Daerah dan masyarakat untuk lebih mengembangkan kegiatan dimaksud kearah yang lebih sempurna.

Seiring perkembangan ilmu pengetahuan dan teknologi serta perkembangan media massa yang mengajikan kegiatan-kegiatan keagamaan yang disajikan oleh beberapa stasiun televisi swasta, dengan daya tarik beberapa kegiatan seperti lomba tahfiz dengan peserta anak-anak berusia dibawah 10 tahun, berdasarkan hal tersebut, pemerintah Kabupaten Tanah Datar, kementerian agama Kabupaten Tanah Datar dan LPTQ Kabupten Tanah Datar berusaha mempelajari dan mengaplikasikan dalam bentuk pembinaan khusus kegiatan tahfiz yang dimulai dengan kegiatan "WAKAF 1000 HAFIDZ" yang di ikuti oleh para santri/wati, dan peserta didik pada pendidikan dasar dan menegah di Kabupaten Tanah Datar.

Gambar: 01 


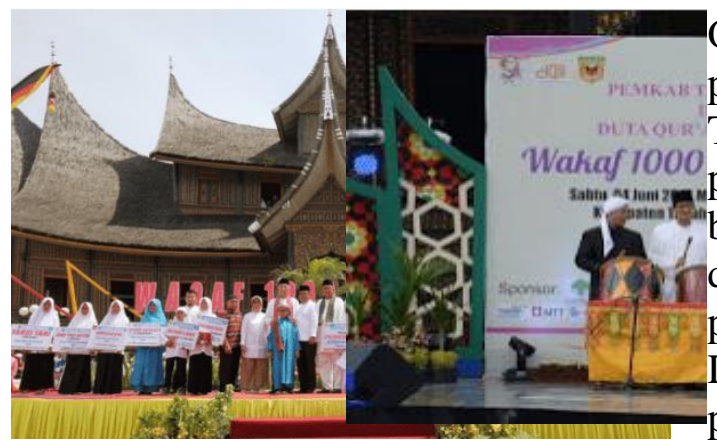

Sumber data: RT Daarul Jannah Gambar: Kegiatan Wakaf 1000 Hafiz Tanah Datar

Dampak dari kegiatan tersebut adalah dengan berdirinya "rumahrumah tahfiz" di berbagai tempat di Kabupten Tanah Datar, baik yang dikelola secara pribadi maupun secara bersama melalui Taman Pendidikan Al-quran yang ada di setiap daerah di Kab. Tanah Datar, hal ini termasuk "Rumah Tahfiz Daarul Jannah" nagari Tanjung Barulak Kecamatan Batipuh Kab. Tanah Datar

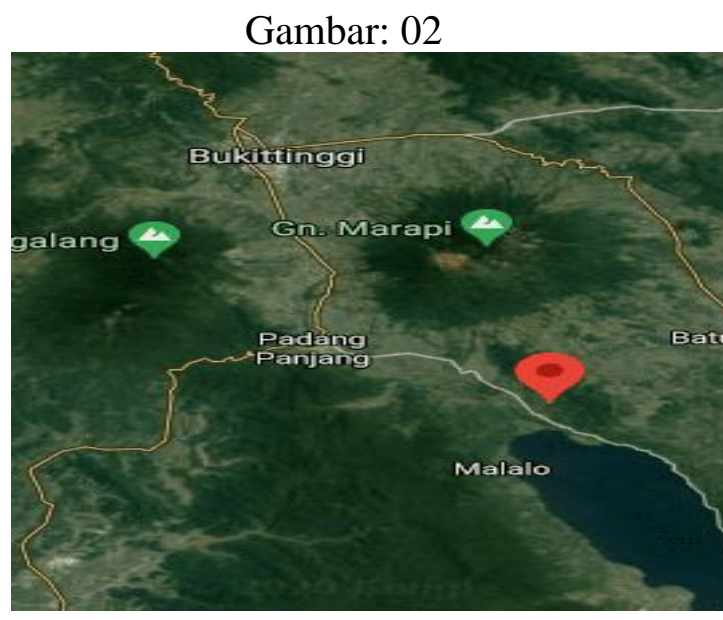

Sumber data: Goggle Map

Dalam mengembangkan peran dari pondok dan/rumah Tahfidz, maka penelelitian ini akan melihat hasil penelitian terdahulu. Diantaranya penelitian yang dilakukan oleh Eva Fatmawati (2019) yang menyatakan bahwa Pondok Pesantren Al-Ashr AlMadani merupakan pondok pesantren yang memiliki konsep dengan memfokuskan terhadap Tahfidzul
Qur'an, hal yang menjadi permasalahan di dalam program Tahfidz Al-Qur'an tersebut dalam proses pembelajaran, terlihat dari belum sesuainya metode yang digunakan dalam manajemen pembelajaran Tahfidz Al-Qur'an. Dengan kesimpulan bahwa, pondok pesantren Al-Ashr Al-Madani merupakan Boarding School dengan berbasis pada tahfidzul Qur'an. Perencanaan dilakukan dengan empat tahapan seleksi, pengorganisasian dengan menentukan tugas dan mekanisme dalam proses pembelajaran, pelaksanaan ditandai dengan adanyan proses belajar mengajar, pengawasan dengan melakukan pemantauan melihat buku setoran santri dan mengabsen santri, faktor pendukung ialah dari lingkungan pondok pesantren, yang menghambat kurangnya istiqomah santri dalam menghafal tahfidz al-Qur'an . Dan Keberhasilan yang diraih Pondok Pesantren Al-Ashr Al-Madani dapat dilihat dari hasil prestasi dengan mengikuti perlombaan Tahfidz $\mathrm{Al}$ Qur'an berbagai tingkatan dan kejuaraan, lebih lanjut Fitriani dan Aulia Nisa (2017) mengatakan bahwa Kinerja Guru Tahfidz dalam Program Tahfidz Quran menunjukan bahwa, kinerja guru tahfidz dalam program tahfidz Quran sudah dalam kategori baik, ini dilihat dari pembinaan guru tahfidz dalam membina siswa menghafal al-quran dengan menggunakan media rekaman imamimam terkenal dan variasi metode pengajaran/pembinaan yang digunakan serta didukung dengan motivasimotivasi yang diberikan kepada siswa agar terus meningkatkan hafalannya dengan sebaik mungkin.Pelaksanaan program tahfidz Quran yang telah 
dijalankan selama kurang lebih 1 tahun belakangan ini juga dalam kategori berjalan efektif, walaupun disamping itu terdapat berbagai macam kendala yang dihadapi, namun program tahfidz quran yang berlangsung sudah cukup baik. Hal ini ditandai dengan perincian yang peneliti temukan di lapangan bahwa Dari 18 siswa, 6 orang sudah menghafal 3 juz, 2 orang masih menghafal 1 juz dan 10 orang sudah menghafal 2 juz yang telah dicapai dalam 1 tahun belakangan ini. Bahkan dalam bulan Ramadhan yang lalu mereka dibimbing untuk menambah hafalannya 1 juz. Guru tahfidz telah melaksanakan upaya-upaya yang sangat baik bagi kemajuan siswa dalam menghafal Al-Quran dan hal ini sangat sesuai dengan tujuan program tahfidz quran yaitu mencetak hafidz/hafidzah yang berkualitas. Dari hasil penelitian tersebut maka penelitian kali ini mengarah kepada peran perempuan dalam penguatan kegiatan keagamaan melalui pemberdayaan rumah tahfiz.

Metode penelitian yang digunakan adalah, metode penelitian kualitatif dengan pendekatan Deskriptif. Metode Kualitatif menurut Haris dalam irwandi (2012) adalah suatu proses penelitian ilmiah yang lebih dimaksudkan untuk memahami masalah-masalah manusia dalam konteks sosial dengan menciptakan gambaran menyeluruh dan kompleks yang disajikan, melaporkan pandangan terperinci dari sumber informasi, serta dilakukan dalam setting yang alamiah tanpa adanya intervensi apapun dari peneliti. Data yang dikumpulkan pada penelitian ini adalah data primer dan data sekunder, informan penelitian adalah; wali nagari, tokoh masyarakat dan masyarakat serta guru tahfiz. Lokasi penelitian ini dilaksanakan di
Rumah Tahfiz Daarul Jannah Nagari Tanjung Barulak Kec. Batipuh Kab. Tanah Datar. Tekhnik pengumpulan yang di gunakan dalam penelitian ini adalah wawancara, observasi lapangan, dan studi dokumentasi. Teknik analisis data yang digunakan adalah analisa data teknik analis data model interaktif

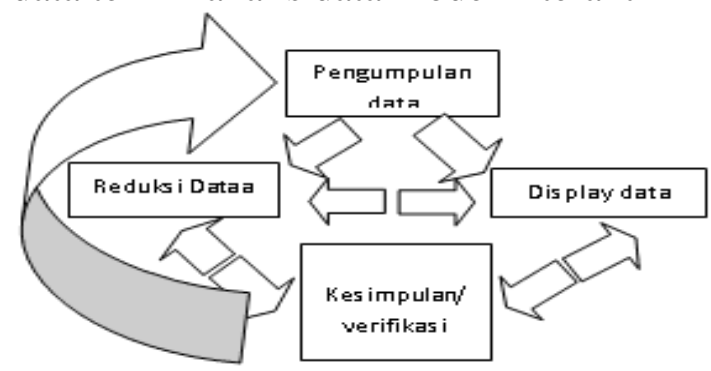

Model Interaktif Miles dan Huberman

\section{HASIL DAN PEMBAHASAN:}

1. Gambaran umum rumah tahfiz (RT) Daarul Jannah

Rumah tahfiz (RT) Daarul Jannah nagari Tanjung Barulak Kecamatan Batipuh Kab. Tanah Datar, berdiri tanggal 9 September 2017 oleh pemerintah nagari, Kerapatan Adat Nagari (KAN),Badan Pemusywaratan Nagari, lembaga unsur, guru Taman Pendidikan Alquran (TPA) dan masyarakat, termasuk warga Tanjung Barulak yang berada di perantuan. Pendirian RT Daarul Jannah di latar belakangi oleh perhatian pemeritah daerah Kabupaten Tanah Datar dalam menggiatkan program Tahfiz di Kabupaten Tanah Datar. Dalam mewujudkan Kabupaten Tanah Datar sebagai Kabupaten Tahfiz maka beberapa program kegiatan telah dilaksanakan oleh pemerintah daerah dengan melibatkan Taman Pendidikan AL-quran sebagai langkah awal dalam pendirian RT ini, sehingga program yang diluncurkan tersebut di sambut baik oleh Pemerintah Nagari Tanjung Barulak dengan mengeluarkan kebijakan yaitu menjadikan Nagari 
Tanjung Barulak sebagai Nagari Tahfiz dengan slogan kegiatan adalah "Gerakan Tanjung Barulak menuju Nagari Tahfiz" dengan memaksimalkan 1 rumah 1 orang hafiz/zah.

Tempat pelakanaan kegiatan dilaksanakan di gedung Panti Asuhan dengan struktur bangunan dua tingkat, tingkat pertama untuk menginap santriwati sedangkan tingkat dua di tempati oleh santri. RT Daarul Jannah diketuai oleh Ibuk Isnaini, S.Ag serta dibantu oleh beberapa oleh guru-guru dengan jumlah santri sebanyak 86 orang dengan guru Pembina sebanyak 13 orang, para santri berasal dari dalam dan luar nagari Tanjung Barulak dengan umur yang berfariasi ulai dari umur pra sekolah (TK) sampai pada umur masa sekolah (SD dan SLTP).

Tabel : 1

Data Pembina keigatan Tahfiz di RT Daarul Jannah

\begin{tabular}{clllc}
\hline No & \multicolumn{1}{c}{ Nama } & $\begin{array}{c}\text { Jenis } \\
\text { Kelamin }\end{array}$ & Jabatan & $\begin{array}{c}\text { Pendidikan } \\
\text { terakhir }\end{array}$ \\
\hline 1 & Isnaini, S.Ag & Perempuan & Ketua & S1 \\
2 & Faurina, S.Iq & Perempuan & Guru & S1 \\
3 & Novi Rosymen, S.Pdi & Perempuan & Gun & S1 \\
4 & Ozi, S.Pd & Perempuan & Gurı & S1 \\
5 & Rabiatul husni, S.Pd & Perempuan & Gurı & S1 \\
6 & Rismiwati & Perempuan & Gurı & SMU \\
7 & Afrizal & Laki-laki & Gurı & MTI \\
8 & Syaiful, S.Pd & Laki-laki & Gurı & S1 \\
9 & Devi Yunita, S.Pd & Perempuan & Guru & S1 \\
10 & Desi Amriani & Perempuan & Gurı & MAN \\
12 & Desi Whahyuni, S.Pd & Perempuan & Gurı & S1 \\
13 & Fauzan & Laki-laki & Gurı & MAN \\
\hline
\end{tabular}

Sumber data: RT Daarul Jannah Gambar: 03

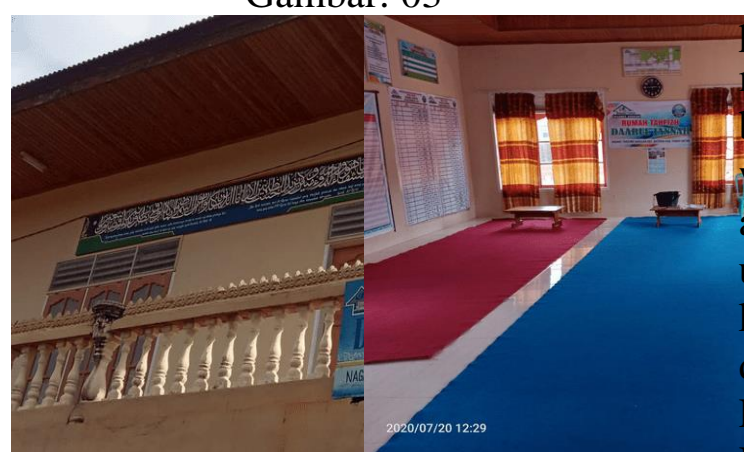

Sumber data: RT Daarul Jannah
Gambar : Gedung dan Ruangan Belajar RT

Sebagai sebuah organisasi RT Daarul Jannah memiliki sturktur organisasi yang berbentuk sederhana dalam rangka menggambarkan sebuah organisasi dikelola sesuai dengan prinsip manajemen yang ada menurut Robbins dan Coulter (2007:284). Struktur organisasi dapat diartikan sebagai kerangka kerja formal organisasi yang dengan kerangka kerja itu tugas-tugas pekerjaan dibagi-bagi, dikelompokkan, dan dikoordinasikan. Dengan adanya struktur tersebut maka diharapkan RT Daarul Jannah dapat melaksanakan seluruh program kerja yang telah disusun serta lebih memudahkan dalam pengendalian organisasi sesuai dengan Tugas dan fungsi masing-masing pengurus.

\section{Pelaksanaan Kegiatan RT Daarul Jannah \\ Pelaksanaan kegiatan keagamaan} di Nagari merupakan salah satu tanggungjawab lembaga unsur yang ada di nagari terutama lembaga unsur alim ulama,(termasuk perempuan) hal ini sesuai dengan fungsi dan kedudukan lembaga unsur dimaksud, menurut Irwandi (2020) bahwa peran dan fungsi lembaga unsur alim ulama (termasuk perempuan) mempunyai posisi yang strategis, terutama dalam memelihata kelangsungan kegiatan bidang keagamaan, sekalugus sebagai wadah_dalam menjaga aqidah umat agar trdaki terpengaruh dari unsurunsur kemurtadan, menjaga kelangsungan syariah Islam sesuai dengan Al-quran dan Sunnah. Pelaksanaan kegiatan Tahfiz di RT Daarul Jannah dilaksanakan pada hari Jumat dimulai 13.30 s/d 16.00 WIB 
dan hari Sabtu dimulai jam $14.00 \mathrm{~s} / \mathrm{d}$ 16.00 WIB, untuk memantapkan hafalan, maka setiap satu bulan diadakan Mabit yaitu pada hari sabtu s/d Minggu.

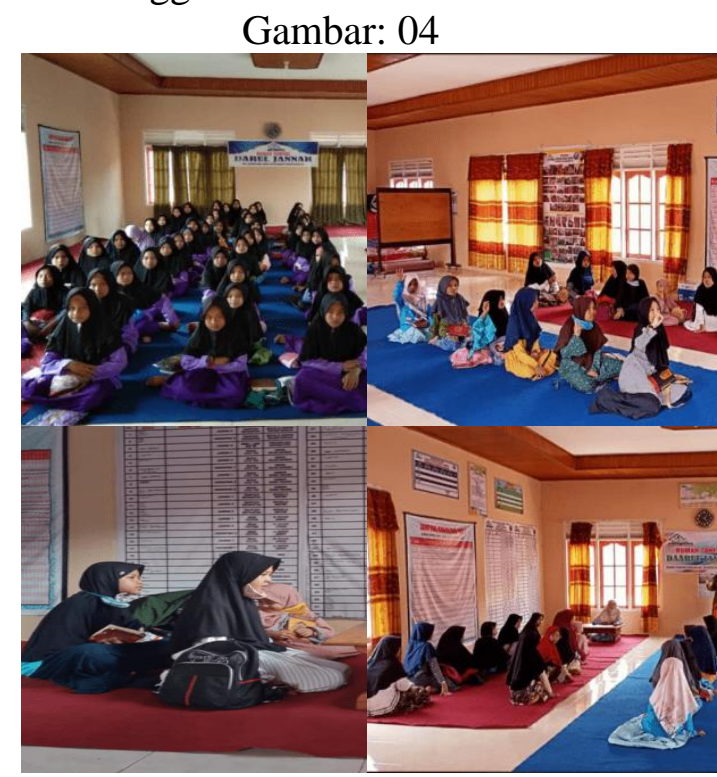

Sumber data: RT Daarul Jannah Gambar : Suasana Belajar Mengajar

Untuk lebih memotivasi para santri dalam menghafal Alquran RT Daarul Jannah juga memprogramkan kegiatan tambahan diantaranya adalah lomba tahfiz antar santri yanag dilaksanakan 3 kali dalam satu tahun, dan santri terbaik akan diberikan Rewarsd serta kegiatan lain seperti mengikuti liga santri dan wisata riligius dengan mengunjungi objekobjek wisata yang ada di Sumatera Barat. Hasil pelaksanaan kegiatan tahfizul Quran dimaksud telah di peroleh beberapa hasil diantaranya; yang sudah Hafal 1 Juz sebanyak 35 orang, yang sudah hafal 2 Juz sebanyak 31 orang, yang sudah hafal 3 Juz 10 serta yang telah hafal 4 Juz sebanyak 9 orang

Gambar: 05

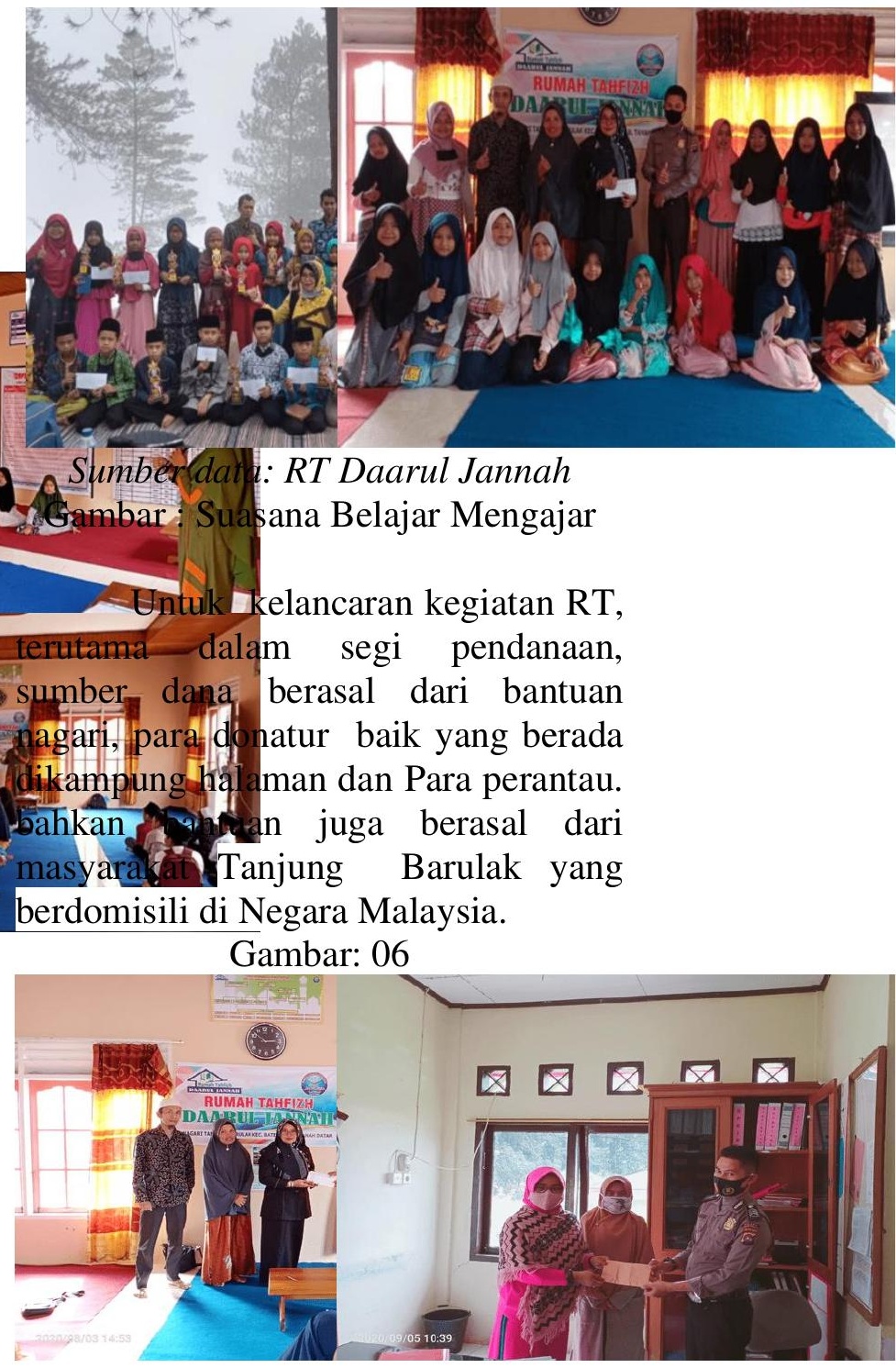

Sumber data: RT Daarul Jannah

Gambar : Bantuan Perantau dari Malaysia

3. Keterlibatan Perempuan Dalam Pembinaan RT Daarul Jannah

Dalam KBBI (2002), perempuan diartikan sebagai manusia yang mempunyai puki (alat kelamin), dapat menstruasi, hamil, melahirkan anak dan menyusui. Dalam membicarakan tentang kedudukan perempuan menurut Mounsour fakih dkk (1996), berbicara tetang perempuan adalah bicara tentang transisi yang 
dibayangkan. Tidak hanya di Indonesia dan tidak hanya di negerinegeri timur, munculnya gerakan Woman's Lib menunjukkan bahwa di bagian dunia yang lebih maju, setuasi transisi itu dibayangkan sebagai kaum perempuan yang lewat perjuangan menghapuskan kesejangan, diinginkan mearaih kedudukan setara dengan kedudukan lawan jenisnya.

Dalam Al-quran Allah SWT berfirman:

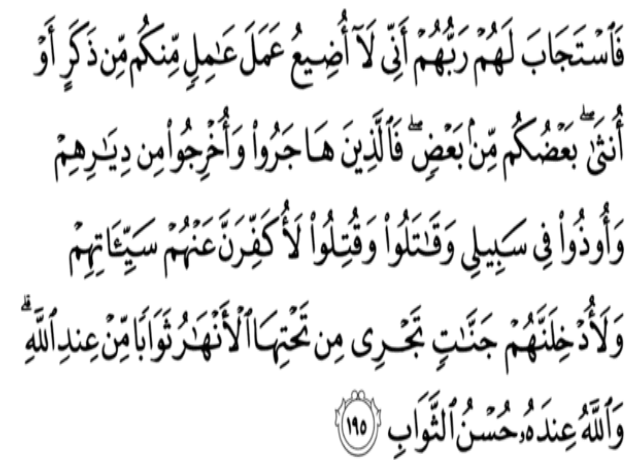

"maka tuhan mereka telah memperkenankan permohonannya (dengan berfirman)"sesungguhnya aku tidak menyia-nyiakan amal orangorang yang beramal di antara kamu, baik laki-laki atau perempuan, (karena) sebagian kamu adalah turunan dari sebagian yang lainy. Maka orang-orang yang berhijrah, yang diusir dari kampong halamannya, yang disakiti pada jalan- $\mathrm{Ku}$, yang berperang dan yang dibunuh, pastilah akan $\mathrm{Ku}$ hapuskan kesalahan-kesalahan mereka dan pastilah Aku masukkan mereka ke dalam surge yang mengalir sungaisungai di bawahnya, sebagai pahala di sisi Allah. Dan Allah pada sisi-Nya pahala yang baik (Q.S Alim Imran 3: 195)

Dalam tafsir Kementerian Agama Republik Indonesia dijelaskan bahwa Allah Swt tidak akan menyia-nyiakan amal seseorang yang taat dan tidak akan membeda-bedakan antara laki- laki dan perempuan dalam member pahala dan balasan, karena kedua jenis ini satu sama lain turun menurunkan, perempuan berasal dari laki-laki dan begitu juga sebaliknya.

Keterlibatan Kaum Perempuan dalam kegiatan-kegiatan Sosial kemasyarakatan sangat penting dalam mengingat fungsi dan kedudukan yang sama dengan kaum laki-laki. Menurut Irwandi (2020), peran Perempuan dalam kegiatan sosial keagamaan sebagai berikut; pertama Perempuan sebagai anggota "Cadiak Pandai" artinya posisi keilmuan antara kaum laki-laki dengan perempuan ditempatkan pada posisi yang sama di Daerah Minangkabau, Kedua. Perempuan sebagai "Bundo Kanduang" artinya; kedudukan ini mengisyaratkan bahwa sikap dan tindak tanduk perempuan di Minangkabau mencerminkan kualitas akhlah baik di rumah tangga maupun di nagari dan masyarakat dan ketiga, perempuan sebagai "bundo kanduang Organisasi" artinya perempuan juga mempunyai kemampuan dalam memimpin sebuah organisasi, tampa meninggalkan tanggungjawabnya sebagai bundo kanduang di tengah-tengah keluarga.

Menurut Munawar Chalil (1984). Perempuan itu, kecuali tergolong bangsa manusia, juga ia diberi hak oleh tuhan yang tidak berjuang dengan hak yang diberikan kepada kaum lelaki, hanya dalam beberapa perkara juga kaum perempuan, karena menang dari asal mula kejadiannya sudah dijadikan berlainan/berbeda. Berkenaan dengan keterlibatan Perempuan dalam kegiatan kemasyarakatan, terutama kegiatan bidang sosial keagamaan, dapat merujuk pada kesetaraan gender, Nelien Hspels dkk (2005) mengatakan kesetaraan gender dapat merujuk 
kepada kesamaan hak, tanggungjawab dan kesempatan bagi laki-laki dan perempuan serta anak laki-laki dan anak perempuan. Kesetaraan gender meliputi hak asasi dan hak pekerja yang sama. Dan kesetaraaan nilai dan distribusi tanggungjawab, kesempatan, beban kerja serta pengambilan keputusan yang adil . lebih lanjut pada saat ini masyarakat sangat membutuhkan peran perempuan dalam berbagai aspek terutama pada aspek pendidikan, karena pada aspek ini masyarakat masih mempercayai perempuan masih memiliki kemampuan dalam membina generasi muda dengan segala pendekatan psikologis yang dimiliki. Indah Ahdiah (2013), mengemukakan bahwa perempuan dalam menjalankan perannya dalam masyarakat tergantung pada budaya masyarakat dimana ia tinggal. Dari sudut pandang peran antara laki-laki dan perempuan, keduanya sama-sama melaksanakan peran dalam ranah domestic, publik dan sosial, mnamun dalam kenyataannya, peran domestic lebih banyak ditanggung oleh perempuan.

Berdasarkan hal tersebut jelas keterlibatan Perempuan (Bundo Kanduang) sangat penting dalam menjalankan kegiatan Keagamaan khususnya di Sumatera Barat. Hal ini tidak bertentangan dengan adat istiadat yang berlaku di tempat dimana perempuan menjalankan aktifitas keagamaannya.

Keterlibatan Perempuan dalam kegiatan rumah Tahfiz Darul Jannah sangat jelas dan hal ini dibuktikan dengan komposisi pengajar/pendidik/Ustadz yang lebih banyak dibandingkan dengan kaum laki-laki. Hal ini juga terlihat dari kepemimpinan perempuan dalam manajemen kegiatan yang di pimpin oleh perempuan. Keterkaitan peran perempuan dalam segi budaya atau kebiasaan setempat, memperlihatkan kondisi yang konusif dan tidak menjadi pertentangan di tengah-tengah masyarakat khususnya di Nagari Tanjung Barulak, bahkan setiap kegiatan yang dilaksanakan mendapat dukungan penuh dari masyarakat maupun dari perantau.

\section{KESIMPULAN:}

Perempuan dalam kegiatan keagamaan di Sumatera Barat khususnya di nagari Tanjung Barulak mendapatkan tempat yang spesifik ditengah-tengah masyarakat. Perempuan di Nagari ini tidak hanya beraktifitas di Rumah Tangga sebagai Limpapeh Rumah Gadang, ibu bagi anak-anak di rumah tangga tetapi juga sebagai "ibu" bagi anak-anak di Nagari. Salah satu peran yang dimainkan adalah sebagai Pembina dan pengayom kegiatan pembelajaran dan pendidikan dibidang Tahfizul Quran. Salah satu indikator yang dapat dijadikan rujukan adalah banyaknya dukungan baik moril maupun materil dari masyarakat baik yang berada di kampung halaman maupun diperantuan. Dan dari hasil yang diperoleh dari kegiatan tahfizul Quran tersebut, RT telah dapat menjalankan kegiatan dengan hasil sebagai berikut: yang sudah Hafal 1 Juz sebanyak 35 orang, yang sudah hafal 2 Juz sebanyak 31 orang, yang sudah hafal 3 Juz 10 serta yang telah hafal 4 Juz sebanyak 9 orang. Keterlibatan kaum perempuan dalam kegiatan ini memperlihatkan hasil peran yang sangat signifikan hal ini memperlihakan tidak adanya pertentangan dalam membina umat antar kaum laki-laki dengan kaum 
perempuan dalam segi keagamaan, dari segi adat istiadat Minangkabau pun, peran perempuan juga mendapat tempat tersendiri, adalkan bisa berperan dalam dua fungsi yaitu fungsi sebagai Ibu atau Bundo Kanduang di Kaum dan Keluarga juga sebagai Bundo Kanduang Di tengah-tengah umat.

\section{REFERENSI:}

Robbins, S dan Coulter, M. 2007, Manajemen., Jakarta : PT Indeks.

Depdiknas, Kamus Besar Bahasa Indonesia, (Jakarta, Balai pustaka, 2002

Eva Fatmawati, https://journal.uinsgd.ac.id/ind ex.php/isema/article/view/525 $\underline{5}$, Archives $>$ Vol 4, No 1 (2019)

Fitriani,https://journal.iainlangsa.ac.id/i ndex.php/ikhtibar/article/view/ 322 Vol 4 Nomor 2 (2017)

Indah Ahdiah, Peran-Peran Perempuan Dalam Masyarakat, dalam Jurnal Academica Fisip Untad Vol.05, Nomor 2, (2013), 1085.

Irwandi (2020) Eksistensi Lembaga Unsur Alim Ulama (Pemberdayaan Kegiatan Keagamaan di kenagarian) http://ecampus.iainbatusangka r.ac.id/ojs/index.php/alfuad/art icle/view/2079 $\mathrm{Vol} 4$, No 1 $\underline{(2020)}>$ Irwandi

Irwandi (2020), penguatan peran perempuan sebagai "cadiak pandai"dan "bundo kanduang" dalam Kegiatan Didikan Subuh, https://journal.uinmataram.ac.i d/index.php/qawwam/article/v iew/2353/1255

Kementerian Agama Republik

Indonesia

https://risalahmuslim.id/quran/ ali-imran/ 3-195/

Mounsour fakih dkk, Membincang

Feminime : Diskursus Gender Persepektif Islam (Surabaya:

Risalah Gusti, 1996)

Munawar Chalil, Nulai Wanita

(Solo:Ramadhani, 1984)

Munir Amin, Ilmu Dakwah: (Jakarta: Amzah, 2013), Cet Kedua Sambas Syukriadi, Ilmu Dakwah (Kajian Berbagai Aspek, 2004): (Jakarta: Pustaka Bani Quraisy), Catakan Pertama 